Equity and health

\section{Who cares about health for all in the 21 st century?}

Fran Baum

This paper regrets the retreat in the 1990s from a focus on health as a social good that results from good social policy. It highlights the importance of the People's Health Movement and the WHO Commission on the Social Determinants of Health as offering a chance to return to a more socially just quest for equity and health.

t's 's been a peculiar century so far. It started off with the great and lofty thoughts that accompany centennial change. Millennium summits, domes, and plans for a peaceful century in which human health and wellbeing blossomed. With amazing rapidity, in the wake of 11 September 2001, it deteriorated into a century of fundamentalisms, acute fear of terrorism, and an unprovoked attack on a sovereign state that was not backed by the United Nations or the majority of citizens of the countries going to war. The aftermath of the war in Iraq has become a public health nightmare ${ }^{1}$ and there are few signs of the flourishing of democracy that was meant to justify the war. Meanwhile the deeper causes of global instability persist and the USA spends more on war than it does on tackling extreme poverty. Sachs estimates that eight million people die each year because they are too poor to stay alive. ${ }^{2}$ The 2 lst century, then, is proving to be a disaster for Africa and many other postcolonial states who face economic disaster under the burden of crippling debt and the onslaught of both old (such as malaria) and new infectious diseases (most notably HIV/AIDS). Life expectancy in Africa is going backwards for the first time in over a century. ${ }^{3}$ Meanwhile the populations of OECD countries are experiencing growth in wealth and prosperity, albeit with increasing inequities between the rich and poor. ${ }^{4}$

\section{IMPORTANCE OF VISIONARY LEADERSHIP}

It is against this background that I pose the question: who cares about Health for All in this century? The answer would have been easier if we had gone back 25 years to the period around 1980. The World Health Organisation under the charismatic leadership of Dr Halfdan Mahler had launched the Health for All by the Year 2000 campaign $^{5}$ and the target seemed a real possibility. The WHO was widely respected as a lead organisation in global health with a leader who was visionary and inspiring. Many public health doctors now in their 50s and 60s remember with affection the great inspiration they received from the HFA2000 strategy. Mahler's leadership lasted through to the 1980s when the Ottawa Charter for Health Promotion ${ }^{6}$ inspired more people to adopt a comprehensive model of promoting health that did not blame individuals but rather focused on creating environments and making policies in which people could flourish and make easy, healthy choices. I remember my own excitement on reading the Ottawa Charter and seeing that it could move health promotion beyond simple ineffective behaviour change strategies to whole of community approaches to improving wellbeing. There was a buzz in public health then, a palpable feeling that we were on the right track with Healthy Cities, Healthy Schools, and other such initiatives, comprehensive primary health care plans, community involvement, and a growing (if fragile) commitment to equity in health.

Sadly, much of this idealism was lost in the 1990s. WHO lost its ability to inspire and seemed to give up its leadership in global health to the World Bank. This was most obvious in 1993 with the publication of the World Bank's Investing in Health. ${ }^{7}$ This report saw health as a crucial part of economic development but did not see health as a human right. This approach was consolidated with the notion of disability adjusted life years (DALYs) that privileged the value of lives of those who were young and without disability. ${ }^{8}$ These approaches to health were very much in line with the zeitgeist of neoliberalism that led to the devastating economic prescription of structural adjustment throughout the developing world-completely without an evidence base or sound justification. The WHO did nothing to challenge this neoliberalism and seemed to endorse the general direction with its Commission on Macro-economics and Health. ${ }^{9}$ In fact the main challenge within public health came from outside governments and international agencies. It came from grass roots and activist movements who despaired at the direction of global health and came together in December 2000 in Savar Bangladesh at the People's Health Assembly.

\section{FIRST PEOPLE'S HEALTH ASSEMBLY AND PEOPLE'S HEALTH MOVEMENT}

This was truly a civil society movement that had roots in popular people's organisations from around the globe. At this assembly the 1500 people attending provided testimonies of the impact of neoliberalism on their lives, health, and wellbeing. These testimonies were combined with analysis of the global economic trends and the role of major public health institutions such as the WHO and World Bank. Topics discussed included: the ways in which the international regime that governs global trade is fundamentally unfair and biased against poor countries; the impact of unsustainable environmental practices; and the need for a return to people centred primary health care that focuses on the development needs of communities and not on disease focus strategies imposed from outside. The People's Health Movement ${ }^{10}$ emerged from this event. Its philosophy and approach to global health is laid out in the People's Health Charter, which has been translated into 42 languages. In July 2005 the Second People's Health Assembly takes place in Cuenca, Ecuador $^{11}$ and promises to be a major milestone in the road back to a public health based on the needs of ordinary people rather than on the demands of a neoliberal economic fundamentalism.

The catchcry of the Second People's Health Assembly is "The Voices of the Earth are Calling!" This captures the grass roots nature of the movement. The health of the world's indigenous people will receive special focus at the assembly. In so many ways indigenous people highlight what is wrong with our approach to health. Australia exemplifies this well. It is one of the world's richest countries yet the life expectancy of its indigenous peoples is 20 years less than non-indigenous Australians. Instead of being celebrated as the first peoples of the land and given special status, colonial and racist ideas have led to systematic policies that have seen indigenous people deprived of their land and culture, stolen from their families, excluded from the economic benefits of the mainstream, and then blamed and vilified when their health suffered as a 
result of the cruel and inhuman policies. $^{12}$ Blatant injustices such as this provide the fuel and passion for the People's Health Movement.

\section{GLOBAL CIVIL SOCIETY CARES}

The other signs of caring about achieving health for all in the 21 st century come from the "Make Poverty History" campaign with the goals of "trade justice, drop the debt, more and better aid" ${ }^{13}$ The campaign focuses on the 2.8 billion people (nearly half the world's population) who live on less than US $\$ 2$ per day. It is driven by a range of non-government organisations and global campaigners such as Sir Bob Geldof and calls directly on the G8 countries to drop debt for the most heavily indebted nations and for aid to be increased to $0.7 \%$ of GDP as recommended by the UN Millennium Summit. ${ }^{13}$ Achievement of these aims has the potential to make our world healthier and more equitable. But this will only happen if what follows is an approach to health and wellbeing that builds on the early, visionary history of the WHO that recognised that health is not just about the absence of disease but about improving the quality of everyday life in terms of our relationships with each other, the safety and satisfaction of our schools and workplaces, the quality and sustainability of transport and housing, the availability of education, sustainability of the environment, and freedom from violence and war. ${ }^{14}$ So often those who want to do good do not act on this knowledge. Rather they focus on the diseases and believe that tackling them will do the job of creating more health and equity. So we have seen the flourishing of bodies such as the Global Fund and Gates Foundation that, with the best of intentions, set out to tackle a range of infectious diseases. Yet they do very little to tackle the broad social and economic determinants of health that dictate who gets what disease. Healthy people are mainly healthy, not primarily because they have access to good health services (although this helps), but because they have good food, comfortably homes, live in a peaceful environment, have good social support, adequate income, and a satisfying job. The global public health community has to understand and act on this crucial knowledge about what creates health. Are there any signs this may be happening?

\section{SIGNS OF HOPE: SECOND PEOPLE'S HEALTH ASSEMBLY AND WHO COMMISSION ON THE SOCIAL DETERMINANTS OF HEALTH}

It just could be that 2005 may be remembered as the year the social and economic determinants of health began to be taken really seriously globally, nationally, regionally, and locally. In July 2005 the Second People's Health Assembly will take this knowledge as central to its deliberations about how to make the world healthier and more equitable. In March 2005 the WHO launched its own Commission on the Social Determinants of Health (CSDH). ${ }^{15-17}$ This commission will place a primary emphasis on the underlying factors that determine how healthy populations are and how equitably health is distributed within populations. It will emphasise that health services, while crucial, are only one of the determinants of health and that most health gain will come from going upstream to focus on those factors such as employment, housing, quality of living environments, social relationships, and education that are the main determinants of how healthy we are. The commission works on the assumption that creating healthy societies and individuals largely results from action outside the health sector.

The CSDH will use three key strategies to achieve its aims. Firstly, it will establish knowledge networks preliminarily entitled: Priority Public Health Diseases; Child Health and Education; Financing; Human Settlements; Social Exclusion; Employment; Globalisation; Health Systems, Measurement, Gender and Women's Empowerment. Secondly, it will work with countries to ensure action on the social and economic determinants of health. Thirdly, it will work to reform the WHO by ensuring that awareness of the importance of the social and economic determinants of health informs all its work and becomes evident in its response to health issues. The commission has great potential to assist Dr J W Lee, the current director general, to leave as his legacy a reformed WHO that is imbued with a strong understanding and determination to act on the social and economic determinants of health and a public health community that accepts the inevitable logic and sense of designing all interventions based on this understanding.

\section{MAKING SOCIAL DETERMINANTS OF HEALTH CENTRAL}

The path taken by the People's Health Movement and the CSDH is not going to be easy. While more funding has gone into global health in recent years the overwhelming amount of it has gone into disease initiatives that do not tackle the underlying social and economic determinants of health. However, if the People's Health Movement and the CSDH are successful in picking up the baton from the earlier Health for All
2000 movement they may form the vanguard of a successful movement for a socially just and healthier world in which policy decisions are driven primarily by this vision rather than by decisions that maximise profit for a small elite. If the public health community does care about health for all in this century then it must put its full support behind the People's Health Movement and the Commission on the Social Determinants of Health.

$J$ Epidemiol Community Health 2005;59:714-715.

doi: $10.1136 /$ jech.2005.035113

Correspondence to: Professor F Baum, Department of Public Health, Flinders University, GPO Box 2100, Adelaide 5001 Australia; fran.baum@flinders.edu.au

Funding: none.

Conflicts of interest: Fran Baum has been a member of the Global Steering Group of the People's Health Movement since 2000 and was appointed as a Commissioner on the WHO Commission on the Social Determinants of Health in March 2005.

\section{REFERENCES}

1 Roberts L, Lafta L, Garfield R, et al. Mortality before and after the 2003 invasion of Iraq. Lancet 2004;364: 1857-64.

2 Sachs JD. The end of poverty. Economic possibilities for our times. New Jersey: Penguin Books, 2005.

3 Labonte R, Schrecker T, Sanders D, et al. Fatal indifference. The G8, Africa and global health. Cape Town: The University of Cape Town Press, 2004

4 Navarro V, ed. The political economy of social inequalities. Consequence for health and quality of life. Amityville, NY: Baywood Publishing, 2002

5 World Health Organisation. Global strategy for Health for All by the year 2000. Geneva: WHO, 1981

6 World Health Organisation. The Ottawa Charter for health promotion. Health Promotion 1986; 1:i-v.

7 World Bank. World development report 1993: investing in health. Oxford: Oxford University Press, 1993.

8 Anand S, Hanson K. Disability-adjusted life years: a critical review. In: Anand S, Peter F, Sen A, eds. Public health, ethics and equity. Oxford: Oxford University Press, 2004:183-99.

9 Sachs J. Macro economics and health: investing in health for economic development. Geneva: World Health Organisation, 2001, http:// www.cid. harvard.edu/cidcmh/CMHReport.pdf (accessed on 14 Jun 2005)

10 The People's Health Movement. http:// www.phmovement.org (accessed 14 Jun 2005).

11 The People's Health Movement. http://www. phmovement.org/pha2/ (accessed on 14 Jun 2005).

12 Human Rights and Equal Opportunity Commission. Bringing them home: findings of the national inquiry into the separation of Aboriginal and Torres Strait Islander children from their families. Sydney: Human Rights and Equal Opportunity Commission, 1997.

13 Editorial. From Love 8 to G8: only results matter. New Statesman 2005;6 Jun:6-7.

14 Baum F. The new public health. Oxford: Oxford University Press, 2002

15 World Health Organisation. http://www.who.int/ social_determinants/en/ (accessed 14 Jun 2005)

16 Lee JW. Public health is a social issue. Lancet 2005;365:1005-6

17 Marmot M. Social determinants of health inequalities. Lancet 2005;365:1099-104. 
Environmental health

\section{A journal for evidence based policies Ana M Garcia, Carlos Alvarez-Dardet}

\section{The journal of the increasingly relevant.}

T he journal has published in this issue $^{1}$ and in a previous recent issue ${ }^{2}$ two papers with striking evidence relating atmospheric contaminants, and mostly emissions derived from oil based combustion from engine exhausts, with increased risk for children of dying from leukaemia and other cancers. The risk was particularly high for children born in the proximities (up to $1 \mathrm{~km}$ ) of bus stations, but also hospitals and other industrial resources with oil combustion emissions. The results from the different data and several analyses presented in both papers are firmly consistent with the author's conclusions: childhood cancers are strongly determined by prenatal or early postnatal exposures to oil based combustion gases, especially from engine exhausts. Two key points arise from such a conclusion. Firstly, how good is evidence supporting this statement? Secondly, is there an additional argument for stricter control of atmospheric emissions?

Results from both papers, although clearly coherent, are based on data and analysis with some limitations, a common occurrence in epidemiological research, the same category of research that discovered that tobacco causes several health effects and that water born infectious diseases can be effectively prevented. In this case, Knox uses for his analysis a database of children dying from cancer between 1953 and 1980 and maps of emissions for 2001 published by the National Atmospheric Emissions Inventory. Then, most of the putative damaging exposures (prenatal or early postnatal, according to the author) occurred more than 20 years before the data on atmospheric emissions used in the study and, probably, to higher levels of emissions than levels for 2001 in the same places. But this fact does not remove any relevance to Knox's findings: the subsequent questions are how many locations have now emissions similar, or even higher, to those happening several years ago (in UK and in other parts of the remaining world), and how safe are present levels of emissions now.

Another methodological point is that Knox's results are based on mortality data. It will be worth examining also data on childhood cancer incidence (that is, including also child non-lethal cancers): would it be expected to find even higher risks for concerned contaminants? Also, a particularity of Knox analysis is that, as a consequence of the lack of a proper control group, the analysis uses only cases of migrant children (changing address between birth and death). This approach is based on the premise of migration equilibrium around emissions hotspots in the general child population. It would be interesting to test the validity of this approach (analysis of migrants) against confirmed effects of atmospheric emissions. Available data from well established networks of research in this area ${ }^{3}$ could be useful for this testing.

Besides limitations, Knox also finds a clear dose-response association for exposures and childhood cancers, an important criterion for evaluating causality in exposure-damage associations. Another important criterion for causality is consistency. This is to say, if different researchers, observing different populations with different approaches arrive at similar findings, it is probable that the observed association (namely, emissions from combustion from engine exhausts and childhood cancer) is causal, and not casual. This point is crucial for prevention, as only for causal associations will interventions eliminating or reducing exposure be followed by a reduction in the damage frequency or intensity. Knox ${ }^{2}$ quotes studies from USA, Italy, Sweden, and France finding increased risks for leukaemia and other childhood cancer related to residence near high volume roads and petrol and vehicle repair garages. Knox also refers to some studies that have not found any relations. Apparently studies in this area are still scarce, but perhaps there is already enough information for a systematic review or meta analysis properly weighting all available evidence together.

The second point raised at the beginning of this commentary is even more crucial. Should these papers, and other available evidence, be used on behalf of stricter control of oil combustion emissions? Should government and authorities seriously consider these findings and develop any specific actions? And also: could scientific journals play a critical part in decision making processes related to issues affecting people's health, but also strongly depending on political, economical, social, and cultural influences? Well, as much as they can. This journal has deliberately developed an editorial policy focused on publishing the best scientific evidence for socially relevant research on health determinants ("the journal of the increasingly relevant" ${ }^{\prime 4}$ ): the "policy implications" window in articles or the "Evidence based public health policy and practice" section are reassuring proofs of this editorial determination. In a recent editorial ${ }^{5}$ the role of public health policy was examined in its relation with public health research, particularly addressing interventions over gradually augmenting health inequalities. Also poorer people are more likely to live near more contaminating industrial resources.

The gains for health and wellbeing from searching for "appropriate engineering and social solutions" ${ }^{\prime 1}$ to better control toxic atmospheric emissions from oil combustion surpass the expectations of any single study. ${ }^{36-8}$ But also, childhood cancer is an important socially sensitive public health problem and Knox's findings ${ }^{12}$ should be seriously taken into account by decision makers concerned with environmental emissions' limits and control.

$J$ Epidemiol Community Health 2005;59:716-717.

doi: $10.1136 /$ jech.2005.035196

\section{Authors' affiliations}

A M Garcia, Department of Preventive Medicine and Public Health, University of

Valencia, Spain

C Alvarez-Dardet, Department of Public Health, University of Alicante, Spain

Correspondence to: Professor A M Garcia, Facultad de Ciencias Sociales, Avda. Tarongers s/n, 46022 Valencia, Spain; anagar@uv.es

Funding: none.

Conflicts of interest: none.

\section{REFERENCES}

1 Knox EG. Oil combustion and childhood cancers. J Epidemiol Community Health 2005;59:755-60.

2 Knox EG. Childhood cancers and atmospheric carcinogens. J Epidemiol Community Health 2005;59:101-5.

3 Medina S, Plasencia A, Ballester F, et al, on behalf the Apheis group. Apheis: public health impact of $\mathrm{PM}_{10}$ in 19 European cities. J Epidemiol Community Health 2004;58:831-6.

4 Alvarez-Dardet C, Ashton JR. In this issue. J Epidemiol Community Health 2004;58:965

5 Joffe M, Mindell J. A tentative step towards healthy public policy. J Epidemiol Community Health 2004;58:966-8. 
6 Nakahara S, Nakamura Y, Ichikawa M, et al. Relation between increased numbers of safe playing areas and decreased vehicle related child mortality rates in Japan from 1970 to 1985: a trend analysis. J Epidemiol Community Health 2004;58:976-81.

7 Morrison DS, Thomson H, Petticrew M. Evaluation of the health effects of a neighbourhood traffic calming scheme. J Epidemiol Community Health 2004;58:837-40.

8 Tafari L. Lead free. J Epidemiol Community Health 2004;58:966.
Environmental health

\section{Geographically based approaches can identify environmental causes of disease}

\section{Manolis Kogevinas, Neil Pearce}

\section{There is growing evidence to suggest the potential importance of specific environmental exposures in the causation of cancer in children.}

$T$ he causes of child leukaemia and more generally of malignant neoplasms in childhood have been long investigated. Various theories have been proposed on the aetiological mechanisms and risk factors for these neoplasms, including the influence of genetic, prenatal, and postnatal exposures. With a few exceptions, particularly for in utero exposure to ionising radiation and some genetic syndromes, strong and consistent evidence on the importance of specific risk factors has not been produced. One recent exception is the association of ambient air pollution with child leukaemia, an association that is also supported by experimental evidence. For example, a recent experimental study ${ }^{1}$ showed that filtration of particulate matter in ambient air significantly reduced heritable mutation rates in laboratory mice housed outdoors near a major highway and two integrated steel mills. On the other hand, extremely low frequency electromagnetic fields (ELF-EMF) emitted by power lines have received a great deal of attention in recent years, but the evidence of an association with childhood leukaemia remains uncertain; furthermore, even if ELF-EMF are causally associated with child leukaemia they could explain only a very small fraction of all child leukaemias, perhaps around $1 \%{ }^{2}$ Exposure to pesticides, both general and specific, has also been examined extensively in relation to childhood cancers, but the evidence is far from conclusive. ${ }^{3}$

The paper by George Knox in this issue $^{4}$ follows other recent work examining proximity to industrial sources of exposure to toxic atmospheric emissions and childhood cancer. ${ }^{5}$ In this paper he expands on this work by evaluating the effects of specific exposures and their combinations.

Knox applies an approach that differs from that of other studies in two respects. Firstly, the data available are extensive both regarding the number of cases and the number of sources and exposures examined. Secondly, he uses a migration index as the main source for the calculation of the relative risk.

Knox has assembled an impressive combination of records including data on hotspots derived from information on atmospheric emissions, trade directories, and map inspections. He has then used this to examine birth and death records for children dying from cancer and has classified each address with regards to its proximity to hotspots for atmospheric emissions, particularly focusing on migration in and out of hotspots.

The migration index that is used in this analysis could be seen as a type of a case-crossover study design. Children moving houses are examined regarding the distance of their houses from specific sources at birth and at the time of cancer diagnosis. The "case" address is the address the child lived in at the time of birth, and exposures at this time are assumed to be aetiologically relevant to the subsequent cancer. The "control" address is the address that (the same) child lived in at the time of death from cancer, and exposures at this time are assumed to not be aetiologically relevant. If these assumptions are correct, then the informative "case-control pairs" are those in which the "case address" at time of birth and the "control address" at time of death are different. For a particular definition of exposure (for example, living within $1.0 \mathrm{~km}$ of a hotspot), the ratio of the number of discordant "pairs" in which the "case address" is exposed (and the "control address" is not) to the number of discordant pairs in which the "control address" is exposed (and the "case address" is not), yields the odds ratio in a manner analogous to a "matched pair" analysis of a more orthodox case-control study. This in turn can be applied to the overall prevalence of "exposure" among all cases (not just those who moved) to yield an estimate of the population attributable risk.

There are several important assumptions underlying this comparison. Firstly, it assumes that exposures occurring at birth are more aetiologically relevant than those occurring close to the time of cancer diagnosis and death. When this assumption is invalid (for a particular exposure), the findings reported here will also be invalid. In the most extreme case, in which, for a particular exposure, only very recent exposure is aetiologically relevant, the method of Knox will produce the inverse of the true odds ratio. Nevertheless, for most exposures, and for most types of childhood cancer, this assumption is reasonable, and there is also some experimental evidence supporting the importance of early, including prenatal, exposures. ${ }^{6}$ Secondly, Knox's method assumes that there is short term migration equilibrium among the general child population. This assumption would not be valid if, for example, there was a general tendency in the population to move away from environmental hotspots. Thirdly, it also assumes that there is no specific tendency for families to move away from environmental hotspots after the diagnosis of cancer in the child. An attempt to address these latter two assumptions is the restriction of the analysis to short migrations of less than one kilometre. Furthermore, for any such tendencies to produce significant bias they would need to apply to both identified and non-identified environmental hotspots. Many of the exposures considered (for example, hospitals) might be assumed to fall into the latter category. Finally, one must also consider the problems related to exposure misclassification attributable 
to lack of information on duration of residence and in the quantification of environmental exposures, although the resulting misclassification is likely to be non-differential and therefore to produce a bias towards the null. ${ }^{7}$

Notwithstanding these potential problems, the approach followed by Knox is innovative, and the findings are of considerable interest. He shows a number of interesting associations of environmental exposures with childhood tumours. He identifies several specific chemicals as being closely associated with child tumours, particularly butadiene and exposures from internal combustion engines. More than these specific associations, which may or may not be supported by further research, what makes this paper unique is its capacity to combine in a meaningful way a series of routinely collected data on births, deaths, residences, sources of exposures, and specific exposures.

How valid can all this be? More generally, how valid can geographical comparisons be for the identification of the causes of diseases and particularly child tumours? An extensive application of small area statistics was first proposed as a proactive measure after the Seascale leukaemia cluster (Black report). Collection and systematic analysis of such data are undoubtedly important for surveillance within the context of proactive research. However, how efficient has this approach been in identifying new (or old) causes of disease? Or at least what new hypotheses have been generated through the application of small area statistics type approaches? Probably few, at least when small area statistics are applied using comparatively crude exposure scenarios such as homocentric circles around a single point source, as has frequently been the case. There are several reasons why few, if any, risk factors have been identified by applying such approaches. Firstly, many of the environmental exposures examined in relation to cancers and reproductive outcomes such as congenital malformations, are probably not associated with high risks at common environmental levels of exposure. Secondly, such studies entail a comparatively high misclassification of the risk factor(s) of interest and of potential confounders. Finally, many of the hypotheses examined are frequently based on weak a priori evidence and are unlikely to be correct. This latter issue may not be perceived necessarily as a significant problem as small area statistical data are readily available and their use could be seen as a screening tool to test new hypotheses and/or generate them. However, a weak risk factor with a great deal of exposure misclassification is bound to produce weak results, which may not be reproduced, even if the exposure is common and therefore has a comparatively high population attributable risk. Nevertheless, small area based approaches are becoming more attractive as methods evolve, both with regard to the availability of records and methods of statistical analysis. Studies such as those by Knox clearly indicate the potential importance of specific environmental exposures in the causation of cancer in children. It will be important to further investigate these findings, and to further test their validity with other studies that have different methodologies and assumptions.
$J$ Epidemiol Community Health 2005;59:717-718.

doi: 10.1136/jech.2005.036608

\section{Authors' affiliations}

M Kogevinas, Respiratory and Environmental Health Research Unit, Municipal Institute of Medical Reseach (IMIM), Barcelona, Spain and Department of Social Medicine, Medical School, University of Crete, Herakleion,

Greece

N Pearce, Department of Biomedical Sciences and Human Oncology, University of Turin, Italy and Centre for Public Health Research, Massey University Wellington Campus, Wellington, New Zealand

Correspondence to: Dr M Kogevinas, Respiratory and Environmental Health Research Unit, Municipal Institute of Medical Reseach (IMIM), 80 Dr Aiguader Rd, Barcelona 08003, Spain; kogevinas@imim.es

Funding: Neil Pearce's work on this paper was supported by the Health Research Council of New Zealand, and the Progetto Lagrange, Fondazione CRT/ISI. M Kogevinas was partially supported by ISCIII (Red de Centros RCESP C03/09), Madrid.

Competing interests: none.

\section{REFERENCES}

1 Somers CM, McCarry BE, Malek F, et al. Reduction of particulate air pollution lowers the risk of heritable mutations in mice. Science 2004:304:1008-10.

2 Ahlbom A, Day N, Feychting M, et al. A pooled analysis of magnetic fields and childhood leukaemia. Br J Cancer 2000:83:692-8.

$3 \mathrm{Zahm} \mathrm{SH}$, Ward MH. Pesticides and childhood cancer. Environ Health Perspect 1998;106(suppl 3):893-908.

4 Knox EG. Oil combustion and childhood cancers. J Epidemiol Community Health 2005;59:755-60.

5 Knox EG. Childhood cancers and atmospheric carcinogens. J Epidemiol Community Health 2005;59:101-5

6 Greaves M. Childhood leukaemia. BM 2002;324:283-7.

7 Checkoway H, Pearce N, Kriebel D. Research methods in occupational epidemiology. Oxford: Oxford University Press, 2004 path breaking work using the UK Whitehall II study of health in London based civil servants. ${ }^{9}$ Ferrie and her colleagues were able to follow changes in health measurements in a subgroup of men and women whose civil service department was sold to the private sector. In this way, they could take account of possible health differences between those who did and did not experience increasing insecurity before the onset of job change or unemployment. The nature of the reorganisation also meant that to a large extent, civil servants had been "randomised" into the group experiencing greater upheaval in their work situations. 
Research in this area has advanced quickly at a time when, according to many measures, the numbers of secure jobs in the economies of industrialised nations are falling, to be replaced by a variety of more "flexible" types of employment contract. ${ }^{10}$ Perhaps public health advocates are at least as much influenced by the feeling that working conditions are regarded as something that can easily be sacrificed to the gods of economic productivity. ${ }^{11}$

The paper by Artazcoz et al adds to this growing literature in important ways. The authors are well aware of the dangers that people with a tendency towards depression or anxiety may perceive their jobs as less secure. ${ }^{12}$ They are able to show that the relation of less secure employment conditions to health depends on several other factors. One of these is sex. The other is social class (manual or non-manual). Not every kind of insecurity is associated with poorer psychosocial health. The highest excess risk is experienced by those whose contracts have no fixed term, or who have no formal employment contract at all: more or less a "doseresponse relation".

Several recent meta-analyses ${ }^{13}{ }^{14}$ have confirmed the effect of work insecurity on health. Whereas continued insecurity has been found to be a health risk, secure re-employment outside of a declining heavy industrial environment has been found actually to improve health. ${ }^{15}$ Several papers have now concluded from their findings that reductions in job insecurity should be a point of intervention for government policies aimed at improving population health and reducing health inequalities. ${ }^{11}{ }^{16} 17$

$J$ Epidemiol Community Health

2005;59:718-719.

doi: 10.1136/jech.2004.032235

Correspondence to: Professor M Bartley, Department of Epidemiology and Public Health, University College London, 1-19 Torrington Place, London WCIE 6BT, UK;

m.bartley@ucl.ac.uk

\section{REFERENCES}

1 McDonough P. Job insecurity and health. Int J Health Serv 2000:30:453-76.

2 Levenstein S, Smith MW, Kaplan GA. Psychosocial predictors of hypertension in men and women. Arch Intern Med 2001;161:1341-6.

3 Ferrie JE, Shipley MJ, Stansfeld SA, et al. Effects of chronic job insecurity and change in job security on self reported health, minor psychiatric morbidity, physiological measures, and health related behaviours in British civil servants: the Whitehall II study. J Epidemiol Community Health 2002;56:450-4.

4 Power C, Stansfeld SA, Matthews S, et al. Childhood and adulthood risk factors for socioeconomic differentials in psychological distress: evidence from the 1958 British birth cohort. Soc Sci Med 2002; 55: 1989-2004.

5 Mohren DC, Swaen GM van Amelsvoort LG, et al. Job insecurity as a risk factor for common infections and health complaints. J Occup Environ Med 2003;45: 123-9.

6 Winefield AH, Tiggeman M, Goldney RD. Psychological concomitants of satisfactory employment and unemployment in young people.
Soc Psychiatry Psychiatr Epidemio 1988;23:149-57.

7 Winefield AH, Tiggemann M, Winefield HR. The psychological impact of unemployment and unsatisfactory employment in young men and women: longitudinal and cross-sectional data. Br J Psychol 1991;82:473-86.

8 Burchell B. Who is affected by unemployment? In: Gallie D, Marsh C, Vogler C. Unemployment and social change. Oxford: Oxford University Press, 1996

9 Ferrie JE, Shipley MJ, Marmot MG, et al. Health effects of anticipation of job change and nonemployment: longitudinal data from the Whitehall II study. BMJ 1995;311:1264-9.

10 Burchell BJ. The unequal distribution of job insecurity, 1966-86. International Review of Applied Economics 1999:13:437-58.

11 Lavis JN, Farrant MS, Stoddart GL. Barriers to employment-related healthy public policy in Canada. Health Promot Internation $2001 ; 16: 9-20$.

12 Artazcoz L, Benach J, Borrell C, et al. Social inequalities in the impact of flexible employment on different domains of psychosocial health. J Epidemiol Community Health 2005;59:761-7.

13 Bohle P, Quinlan M, Mayhew C. The health and safety effects of job insecurity: an evaluation of the evidence. Economic and Labour Relations Review 2001;12:32-60.

14 Sverke M, Hellgren J, Naswall K. No security: a meta-analysis and review of job insecurity and its consequences. J Occup Health Psychol 2002;7:242-64.

15 Ostry AS, Hershler R, Kelly S, et al. Effects of deindustrialization on unemployment, $\mathrm{re}^{-}$ employment, and work conditions in a manufacturing workforce. BMC Public Health 2001;1:15.

16 Kristensen TS, Borg V, Hannerz H. Socioeconomic status and psychosocial work environment: results from a Danish national study. Scand J Public Health 2002;59:41-8.

17 Bartley M, Sacker A, Clarke P. Employment status, employment conditions, and limiting illness: prospective evidence from the British household panel survey 1991-2001. J Epidemiol Community Health 2004;58:501-6.

\section{Flexible employment and health inequalities}

\section{Fernando G Benavides, George L Delclos}

\section{A flexible labour market could contribute to increasing health inequalities and should be a priority on the public health policy agenda.}

\footnotetext{
$\mathrm{T}$ he relation between flexible employment and health is a recent public health research question. After a long period of progressive labour market regulatory policymaking, particularly in European Union countries, where the influence of trade unions is strong, employers now argue for a supply of a full time workforce that will allow them to compete in a global market characterised by continuous technical and organisational change. In
}

workers in comparison with permanent workers. $^{2}$ Persons who experience frequent job changes are more likely to smoke, consume more alcohol, and exercise less ${ }^{3}$; and workers who perceive job insecurity experience significant adverse effects on their physical and mental health. ${ }^{4}$ Despite some of the limitations of these kinds of studies, primarily in the various definitions of flexible employment (which can be variably defined as job insecurity, frequent job change, or type of contract), the picture regarding this important question is becoming clearer.

In this issue, Artazcoz et al add another piece to this complex puzzle. ${ }^{5}$ The authors examine the possible impact of flexible employment on health inequalities, and show an association between poor mental health outcomes and two forms of flexible employment (non-fixed term temporary contracts and being employed with no contract) that differentially affects less privileged workers: women and male manual workers. 
A further unique contribution of this study is the analysis of the impact of flexible employment on marital and parental status. Workers, especially men, with temporary or no contracts seemed more likely to remain single and not have children. And although few associations were statistically significant, they do open research to study the possible role of flexible labour markets on low birth rates, a common problem of developed countries. In this regard, it will be interesting to consider the effect of flexible employment on single parents, especially women, as the analysis of children living at home was restricted to persons in the survey who were married or cohabiting. Given the increasing frequency of single parenthood in developed countries, and the possibility that an association between being a single parent and being engaged in precarious employment could conceivably go in either a positive or inverse direction (in fact, constituting an example of "reverse causation"), this issue should be examined more closely in future studies.

The next research question is to explore the mechanisms that could underlie the associations identified by this study. Why are some forms of temporary contracts associated with poor mental health? Are they attributable to more hazardous working conditions, to a lack of job experience or to both? Are temporary workers, with their resulting greater job vulnerability, exposed to more stressful circumstances than permanent workers? In addition, other mechanisms related to precarious employment such as the organisational characteristics of the workplace (lack of unionisation or social benefits), or discrimination by both supervisors and permanent workers, should also be examined in future analyses.

It is true that not all flexible employment will have a negative effect on health. Among highly educated workers, such as managers and professionals, a flexible labour situation could be beneficial because job changes may be voluntary or reflect the initial stages of a professional career, or both. This is, in fact, suggested in the study, which found that the association between flexible employment and mental health status varied as a function of social class, mostly affecting less privileged workers. However, if this were true, then an added undesired effect of the flexible labour market could be that it contributes to increasing health inequalities among social classes. It has been previously established that the workplace is one origin of health inequalities $^{6}$; this finding would add the labour market as another predictor of health inequalities, a clear priority on the public health policy agenda.

$J$ Epidemiol Community Health 2005;59:719-720.

doi: $10.1136 /$ jech.2004.032227

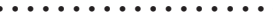 \\ Authors' affiliations}

F G Benavides, Occupational Health Research Unit, Department of Health and Experimental Sciences, Universitat Pompeu Fabra, Barcelona, Spain

G L Delclos, Southwest Center for Occupational and Environmental Health, University of Texas School of Public Health, Houston, Texas, USA

Correspondence to: Professor F G Benavides, Occupational Health Research Unit, Department of Health and Experimental Sciences, Universitat Pompeu Fabra, Barcelona, Spain; fernando.benavides@upf. edu

\section{REFERENCES}

1 Benach J, Benavides FG, Platt S, et al. The healthdamaging potential of new types of flexible employment: a challenge for the public health researchers. Am J Public Health 2000;90:1316-17

2 Kivimäki M, Vahtera J, Virtanen $M$, et al. Temporary employment and risk of overall and cause-specific mortality. Am J Epidemiol 2003; 158:663-8.

3 Metcalfe C, Davey Smith, Sterne JAS, et al. Frequent job change and associated health. Soc Sci Med 2003:56:1-15.

4 Ferrie JE, Shipley MJ, Standsfeld SA, et al. Effects of chronic job insecurity and change of job security on self-reported health, minor psychiatry morbidity, psychological measures, and health related behaviours in British civil servants: the Whitehall II study. J Epidemiol Community Health 2002;56:450-4.

5 Artazcoz L, Benach J, Borrell C, et al. Social inequalities in the impact of flexible employment on different domains of psychosocial health. $J$ Epidemiol Community Health 2005;59:761-7.

6 Vathera J, Virtanen P, Kivimäki M, et al. Workplace as an origin of health inequalities. J Epidemiol Community Health 1999;53:399-407.

\section{THE JECH GALLERY}

\section{Trojan mice in global health issues}

F reyer (http://www.mice.com) uses the imagery of Trojan mice, (small, well focused, and easily manoeuvrable initiatives focused on building creative relationships between existing systems and components) to reflect the complex adaptive systems theory principle that change is not incremental and small inputs can have unexpectedly large return. I use this "Trojan mouse" (gift with a hamburger meal) for engaging students in discussions about the imbedded health related issues of marketing to children, fast food consumption, and the effects on workers' health in outsourcing manufacturing to countries reliant on child and prison labourers.

Correspondence to: Dr Cary A Brown, School of Health Sciences, University of Liverpool, Johnston Building, Brownlow Hill, Liverpool L69 3GB, UK; cabrown@liv.ac.uk

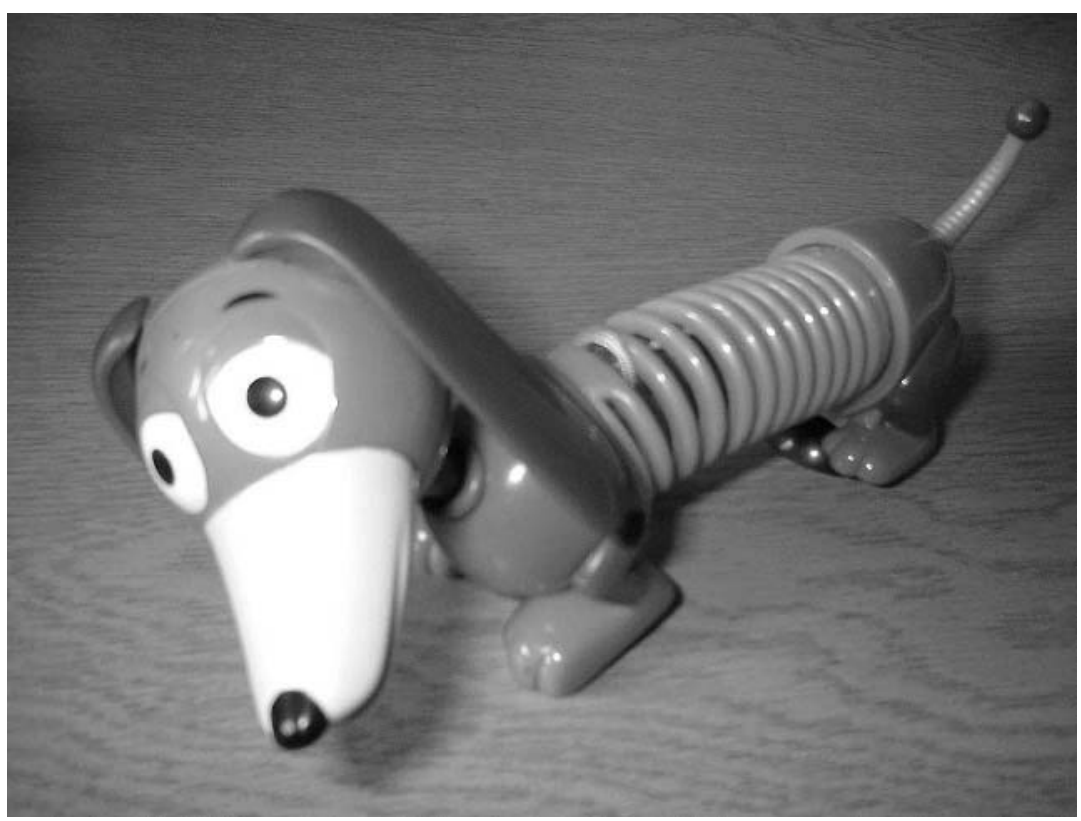

